\title{
Compartmentalization, Resource Allocation, and Wood Quality
}

\author{
Kevin T. Smith
}

Published online: 1 February 2015

(C) Springer International Publishing AG (outside the USA) 2015

\begin{abstract}
The concept of a trade-off of tree resources between growth and defense is readily grasped. The most detailed development of the concept is for the growth-differentiation balance hypothesis that predicts that resources for normal growth and primary metabolism are diverted to support plant defense and secondary or stress metabolism. This hypothesis has been applied to the biosynthetic cost of stress metabolites that protect wood and foliage from herbivory. This review suggests that the trade-offs of primary to stress metabolism is an ongoing theme throughout the evolution of land plants. This review extends the concept of the growth/defense trade-off to processes of apoptosis in the constitutive development of tracheary elements and heartwood as well as to the induced boundary-setting processes of compartmentalization of decay in living trees. For wood utilization, the confusion of heartwood with wound-initiated discoloration continues to obscure the sources of value loss, particularly for high-value hardwood lumber. Examples are drawn from the anatomical effects of tree injury from fire, storms, and vascular wilt disease.
\end{abstract}

Keywords Wood discoloration - Growth-differentiation hypothesis $\cdot$ Heartwood formation - Vascular wilt disease . Mineral stain $\cdot$ Fire damage $\cdot$ Secondary metabolism

\section{Introduction}

Plants face an existential dilemma in the allocation of internal resources to individual survival and reproductive effort. Plants

This article is part of the Topical Collection on Physiological Processes

K. T. Smith $(\bowtie)$

United States Department of Agriculture Forest Service, Northern

Research Station, 271 Mast Road, Durham, NH 03824, USA

e-mail: ktsmith@fs.fed.us must grow fast enough to compete for light, water, and essential mineral elements while providing defense against pests, pathogens, and episodically or chronically adverse environments. While annual plants may require active defense for a single growing season lasting 1 year or less, the challenge of temperate zone trees includes the frequent potential for great size and long life with periods of annual growth and apparent dormancy. Although the concept of a growth/defense trade-off in the allocation of resources is readily grasped, the validity and breadth of applicability of the concept are still being assessed [1].

The most frequently cited example of a growth/defense trade-off involves chemical biosynthesis to protect foliage and wood from herbivory. Various competing schemes for the theoretical and mechanistic basis of the trade-off continue to be tested $[2,3]$. One of the dominant schemes is the growthdifferentiation balance (GDB) hypothesis extended by Herms and Mattson [4] to describe the trade-off in within-tree allocation between tree growth and protection from herbivory.

Compartmentalization of decay in trees represents a set of resource trade-offs that includes both the programmed loss of wood function and the diversion of tree energy resources through biosynthesis. This review presents the compartmentalization process in the wood of living trees: (1) as a critical conceptual example of resource allocation trade-offs and (2) as a major factor for tree health and wood quality.

\section{Metabolism and Specialization}

Growth results from primary metabolism: the photosynthetic capture of solar energy and atmospheric carbon which is fixed into sugar, respired to yield metabolic energy, and converted into other organic compounds. These compounds include structural and non-structural carbohydrates, amino acids for protein, and nucleotides for energy transfer compounds (e.g., ATP) and the genetic code (DNA and RNA). Under 
conditions of attack, infection, or abiotic stress, the tree shifts the allocation of energy and biosynthetic feedstocks to defensive processes. This diversion of photosynthetic carbon compounds and associated energy costs is traditionally termed "secondary" metabolism. This review uses the term "stress metabolism" for those pathways to reduce minimization of their central role for organism survival.

The structure and function of present-day forest flora are the legacy of lasting trade-offs in resource allocation. Natural selection acts on reproductive performance and not directly on individual traits [5]. Allocation trade-offs extend the ecological range or amplitude, but incur an investment cost in stress metabolism. For potentially long-lived forest trees, survival depends at least as much on effective responses to periodic or episodic disturbance as on optimal primary production.

A brief sketch of a few key developments in the long history of trees shows a common theme of success from the diversion of resources from primary to stress metabolism. Stress metabolites such as phenolic acids and complex compounds such as lignin are often assumed to be limited to seed plants (embryophytes) or even more restricted to vascular plants (tracheophytes), the latter containing a vascular system to conduct water and photoassimilates. Although there is some controversy as to the role of convergent evolution or direct descent from a common ancestor [6,7], diversion of carbohydrates to simple phenolic compounds and more complex lignin or lignin-like polymers likely occurred in red and green algae prior to land invasion [8, 9]. Lignin, composed of crosslinked phenolic propane molecules, likely protected algal cell walls and cytoplasm from UV-induced oxidation, mechanical buffeting, and intermittent desiccation of intertidal or coastal zones [10]. Development of these stress metabolites improved the fitness of algae in the prevailing marine or freshwater environment.

Following land invasion, cellular specialization in the development of the stele of prototracheophytes enabled increased height growth and greater competitive exploitation of available sunlight. This specialization included the secondary thickening of cell walls which allowed the tracheary elements (vessel segments and tracheids) to function at negative pressures without collapsing. The tracheary elements also lacked living contents at maturity and functioned with open lumens, greatly improving hydraulic efficiency and flow rates [11]. The open cell lumens result from apoptosis or programmed cell death. Although there are differences in the apoptosis program among cell types, the mechanism for cell death was in place early in the processes of plant evolution and cell differentiation [11].

\section{Tree Development}

The hallmark of broadleaved and coniferous trees is the vascular cambium (VC), the bifacial meristematic layer that divides to form secondary xylem (which matures into sapwood, SW) and phloem (or inner bark) $[12,13]$. The development of the $\mathrm{VC}$ in widely scattered families of woody plants [14] suggests multiple points of origins in the evolutionary routes to modern diversity through the competitive advantage conferred by the growth form of trees.

Both growth and defense depend on two major systems determined by plant cellular structure, the apoplast and the symplast (or symplasm). The apoplast is the continuous system of cell walls, intercellular spaces that may contain air or water, and the lumens of non-living, functional cells. The symplast is the interconnected web of protoplasts or living cell contents distributed throughout the living tree [15].

\section{Sapwood Formation and Heartwood Transformation}

In the woody stem, branches, and roots, the symplast occurs primarily as living parenchyma in the SW. The presence or proportion of living parenchyma in the axial and radial transport system varies among species. As traditionally described, SW is a pathway for water conduction in the apoplast from roots to foliage. Recent research demonstrates the essentiality and diversity of roles performed by the symplast in SW including regulation of apoplastic hydraulic flow, energy storage primarily as starch granules in radial and axial parenchyma, storage and transport of $\mathrm{N}$ and other essential elements, and for dynamic response to wounding $[15,16]$.

Traditionally, heartwood (HW) has been defined as the non-living core of certain broadleaved and conifer species, devoid of stored starch, and containing non-conducting tracheary elements. In addition to position, HW has also been defined on the basis of color due to the impregnation of the HW with extractive substances $[17,18]$ that confer resistance to microbial decay. This report will use the definition supplied by Shigo and Hillis [19] for HW as wood transformed through metabolic changes from SW based on the genetic program for ageing or maturation. This report will use the term discolored wood (DW) for wood discolored by infection and/or tree response to injury and infection [19]. By these definitions, diffuse-porous Acer and Betula do not produce HW but frequently contain DW, depending on wounding history (Fig. 1). The distinction between HW and DW is critical to evaluate growth/defense trade-offs as well as the ability to predict the performance of wood in service and its economic value.

HW formation is another form of apoptosis, the shedding or withdrawal of the symplasm from the inner core of the tree [18]. This withdrawal favors increased growth and greater tree size without a proportional increase in the number or volume of living cells. In heartwood-forming broadleaved and conifer species, living parenchyma in rings of older SW adjacent to the SW-HW interface shift from primary to stress metabolism. 


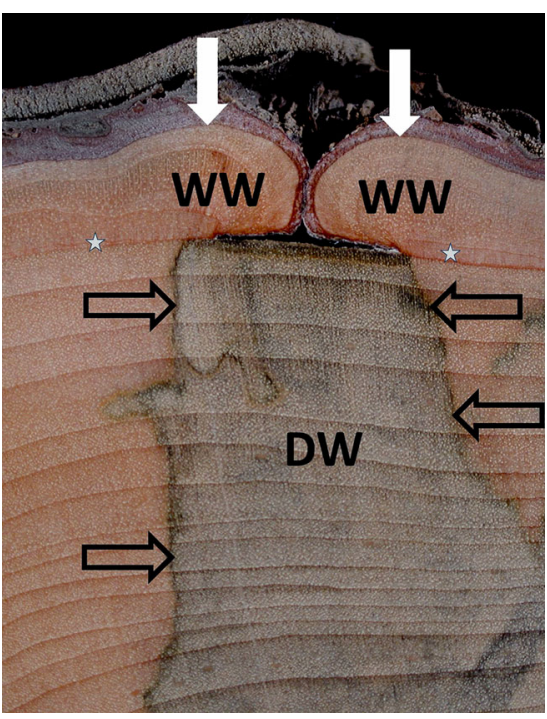

Fig. 1 Transverse section of Acer rubrum. The vascular cambium (white arrow) of the woundwood (WW) has not become confluent. Woundinitiated discoloration (DW) is bounded by reaction zones (open black arrows). A barrier zone is present in the first ring formed after injury (stars)

These shifts mobilize carbohydrate and deplete the axial and radial parenchyma of stored starch. Some of the previously stored energy is diverted to phenolic and terpenoid biosynthesis [18]. Plant phenolics are a highly diverse chemical group derived from the diversion of short-chain energy-rich carbon compounds from sugar metabolism to biosynthesis in the shikimic acid, phenylpropanoid, phosphogluconate, and polyketide pathways [20]. The phenolic products contribute substantially to structural lignin as well as many seasonal pigments and defensive compounds. Part of the defensive processes, for both broadleaved and conifer species, the tannin group of phenolic compounds is widespread in both constitutive protection and induced defense through reaction and barrier zones in the compartmentalization process (see below). Tannins in foliage and wood are reactive pro-oxidant compounds that disrupt both microbial [21] and insect metabolism [22].

Terpene biosynthesis in conifers diverts acetyl- and malonyl-coA from primary fatty acid metabolism to form isoprene which is then modified to enter terpene biosynthesis $[23,24]$. Terpenes are critical for both constitutive protection and induced defense in the Pinaceae [25•]. These programed shifts in metabolism are accompanied by decreased hydraulic conductivity and reduced wood moisture content [19].

\section{Compartmentalization and Closure}

Building on earlier observations of Küster [26], Büsgen and Münch [27], and Hepting [28], Shigo led a pioneering research project that developed the compartmentalization concept [29] to describe the biological basis for patterns of wood staining and decay in living trees. Compartmentalization is a boundary- setting process that resists the loss of normal function and the spread of infection introduced by wounding through the "walling off" of injured and infected tissue. Originally developed for the wood of diffuse-porous broadleaved trees, the concept was soon expanded to include the wood of ringporous broadleaved and conifer species as well as to describe defensive responses in bark (which is beyond the scope of this report). Potential sources of wounding are many, from animal or insect activity, natural shedding of branches, crown injury from storms, or basal injury from human activity and natural hazards. The compartmentalization process has been part of the life of forest trees for a long time and is evident in the fossil record at least back to the Late Triassic [30]. Within the compartmentalization concept, boundaries are both preformed as part of constitutive growth as well as induced at the interface with healthy tissue through shifts to stress metabolism [19, 29, 31•]. The compartmentalization process as an integrated whole continues to evolve as a key concept for forest pathology [32]. Shortle and Dudzik [34] summarized the pioneering research on compartmentalization through a visual summary. Patterns of wood discoloration and decay were identified through the systematic dissection of many mature trees. In living trees, infection that lead to decay is introduced through wounding [33••, 34].

Following wounding, compartmentalization boundaries form in wood present at the time of injury [29, 34-37]. The most immediate boundary is formed by the cavitation, plugging, and tylosis of tracheary elements. Xylem and ray parenchyma shift to stress metabolism and produce phenols and waterproofing lipids in a boundary most frequently referred to as a reaction zone (RZ) (Fig. 2). Frequently, fatty acid

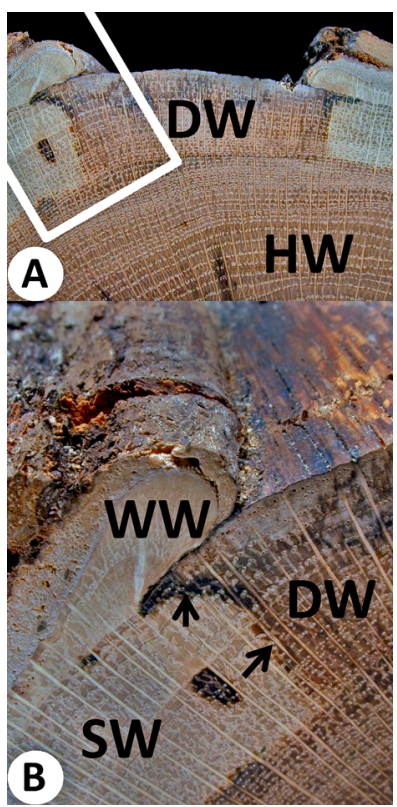

Fig. 2 Transverse section of Quercus alba. a An arc of discolored wood (DW) is located beneath the open wound surface and extends inward to the heartwood (HW). b Inset of A showing the reaction zone (arrows) between the sapwood (SW) and DW 
epoxides such as suberin are deposited in cell walls of the RZ which to protect SW from further desiccation and xylem embolism. The parenchyma of the RZ contain deposits of broadly toxic phenolic compounds [38]. Wood formed in both broadleaved and conifer species by the intact, adjacent VC after injury frequently contains a barrier zone (BZ), a specialized layer characterized by relatively short tracheary elements with greater lignification, fibers, and parenchyma that contain phenolic deposits [39]. DW and eventual decay usually occurs within compartment boundaries [40].

A useful concept for compartmentalization is that the tree breaks the symplasmic connection or "walls off" a volume of previously living SW to resist the loss of hydraulic integrity and the spread of infection. As the infection process is stopped or slowed, the $\mathrm{VC}$ continues to divide and move further from the infection while replacing functional SW at a new spatial position beyond the infection. The apparently healthy tree with a hollow core is the hallmark of successful compartmentalization. Of course, no boundaries or barriers are absolute. Decay pathogens of living trees have various strategies to go around or through RZ and BZ [34, 35, 41]. Successfully, compartmentalized decay infections can breach the BZ if the tree sustains additional injury such as crown loss from storm injury [42] or if the BZ is mechanically breached.

Related to compartmentalization is the process of wound closure that may partially or completely restore continuity of the VC, SW, and phloem along the stem circumference. The closure process usually begins with the formation of a callus pad of undifferentiated thin-walled parenchyma from divisions of dedifferentiated ray parenchyma and VC cells [43] (Fig. 3). A new vascular cambium differentiates within the callus pad, and subsequent cell division produces new xylem and phloem [43]. The newly-formed xylem in woundwood (WW) at the wound margin $[26,43]$ contains tracheary elements that are more narrow and more numerous as well as larger and more numerous as well as larger and more numerous rays and in conifers, with traumatic resin ducts [40, 44, 45]. This cellular differentiation and organization distinguish WW from the initial callus pad. Due to localized hormonal stimulation, annual rings of WW are usually quite wide and taper back to normal thickness at increasing distance from the wound. This localized growth stimulation appears as ribs along the wound margin (Fig. 4). The enhanced ring widths of WW provided added structural support for stems compromized by wounding. The wide WW ribs may also provide compensation for lost SW volume, at least for starch storage. Due to the altered anatomy, hydraulic flow through WW is reduced per unit of cross-sectional area, compared to healthy SW. Wound closure and the formation of a continuous, confluent VC do not always occur, but successful closure does form a continuous, confluent $\mathrm{VC}$ that provides for the production of a continuous band or cylinder of sapwood. Also, wound closure likely results in reduction of oxygen partial pressure within the core of the stem, reducing the activity of aerobic microorganisms such as most wood decay fungi.

As determined by RNA fingerprinting, SW of apparently healthy trees frequently contain latent infections of wood pathogens [46]. This analysis does not resolve whether latent presence reflects successful compartmentalization or the endophytic growth of fungi without triggering the compartmentalization process. Alternative pathways for endophytic infection of wood have not been verified, although initial infection of foliage followed by growth into petioles and branches has been suggested [46].

\section{Critical Differences between DW and HW}

For both DW and HW, symplasmic connections with the rest of the plant are broken. The SW functions of starch storage and water conduction are lost and living parenchyma is absent. HW formation follows a species-specific genetic program of apoptosis that results in the breakdown of the tree symplast. HW formation is often accompanied by programed shifts in metabolic pathways that convert carbohydrate into phenolic and/or terpenoid compounds that contribute to resistance to degradation by pests or decay fungi [18]. In contrast, DW is initiated by wounding and modified by infection. The

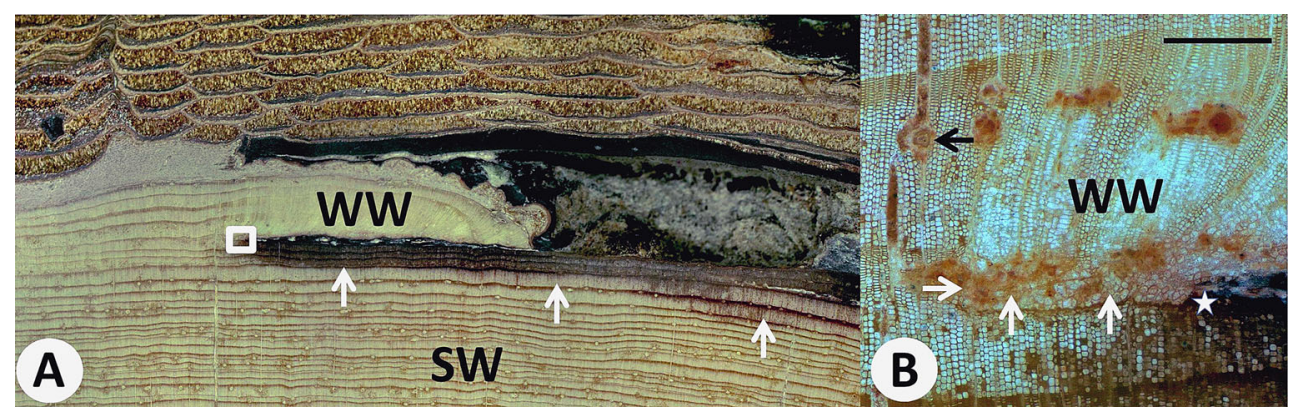

Fig. 3 Transverse section of Pinus ponderosa. a The resin-soaked discolored wood (white arrows) beneath the woundwood and open wound face is quite shallow in the sapwood (SW) band. b Detail from the wound margin of (a) showing the callus pad (white arrows) at the wound margin (star), somewhat disordered woundwood (WW) and the intersection of an axial resin duct and ray (black arrow). Scale bar= $0.5 \mathrm{~mm}$ 


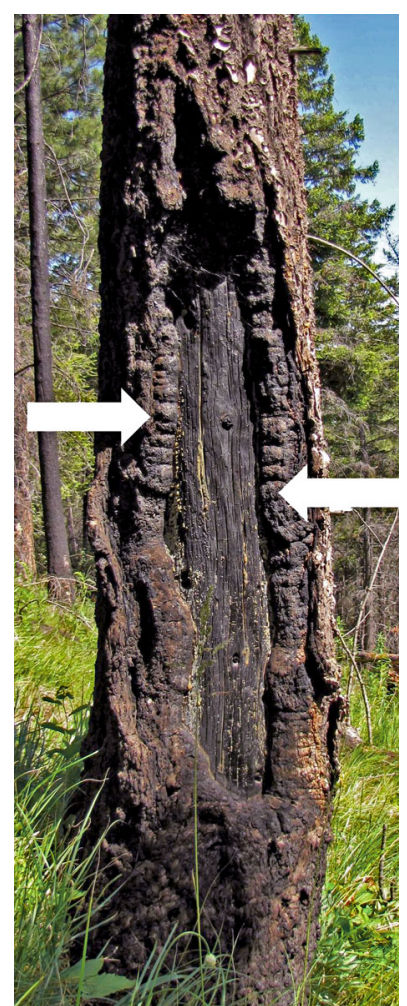

Fig. 4 Open fire scar of Pinus ponderosa. Extensive woundwood ribs (arrows) are present at the margins of the wound

metabolic shifts in DW formation also follow a speciesspecific program, with DW being formed within constitutive and induced compartment boundaries. DW varies in decay resistance relative to SW or HW [47]. Because of similarities in spatial position and color, HW and DW are confused with each other and this confusion continues to complicate evaluation of wood properties, performance, and economic value of products. This confusion can propagate a mistaken sense of mystery about readily understandable patterns of loss of wood quality and value.

For diffuse-porous hardwoods such as Acer, Betula, and Liquidambar, the greatest economic value comes from white "clear" wood. Central cores of DW (known variously as "mineral stain", etc.) in woody stems, roots, and branches of otherwise light-colored wood tend to reduce the value of sawn timber for high-value wood products. Consequently, there is substantial research that attempts to relate the frequency of occurrence of DW in forest stands and the volume of DW within individual trees to environmental factors of climate, soil composition, and drainage [48-51].

Discolored cores were common in 20-year-old and older plantations established in abandoned farmland of a range of Populus species and hybrids in Sweden [49]. In this study, the transverse area of DW (termed "false heartwood") at DBH was not statistically related to poplar clone or soil type. That should not be surprising as those latter two factors would be expected to affect amounts of DW only insofar as they affected the effectiveness of compartmentalization, the wounding history, the radial growth rate, and time elapsed since wounding.

DW production, expressed as "heart size ratio", was not significantly related to stem diameter or geographic region in an investigation of sugar maple sawlogs at various locations in the eastern and north-central USA [50]. Observed and cited associations of heart size to edaphic and climatic factors [50] could readily result from the effects of these factors on compartmentalization effectiveness and growth rates after injury.

Deviating from both traditional terminology as well as that of Shigo and Hillis [19], Baral et al. [51] differentiated SW and putative HW in sugar maple on the colorization of stem disks from surface applications of iodine-potassium iodide $\left(\mathrm{I}_{2}-\mathrm{KI}\right)$ stain. The $\mathrm{I}_{2}-\mathrm{KI}$ colorizes in the presence of starch and the intensity of the color change is a qualitative indicator of stored metabolic energy. As defined by Baral et al. [51], the outer band of starch-containing SW surrounded a middle band of clear white wood with a negative response to the starch stain and termed "heartwood" by these authors. This putative HW surrounded a core of darkly stained "discolored heartwood". Although the concept of physiological distinctions in these tissues is useful, those alternative definitions confuse HW, a protective tissue formed by the inborn genetic program with DW formed in response to previous injury and which has entered the decay process $[29,34]$. The starch stain does not resolve the presence or absence of living cells as such. Also, low levels of starch could be present and not evident in macroscopic view with reflected light. Still, that report [51] does highlight the role of the energy status of the living tree in determining the extent of DW. The choice of terminology becomes less critical as long as the definitions and their implications are clearly stated.

Recent research on the interaction of pathogens and drought on tree mortality bears on resource trade-offs within the compartmentalization process. Oliva et al. [31 $]$ presented a framework to predict the role of pathogens to cause tree mortality under drought conditions based on the nutritional mode of the pathogen. This framework predicts that biotrophs such as rusts and powdery mildews would not be greatly exacerbated by drought unless they were well established prior to drought onset. The metabolically costly $\mathrm{RZ}$ and $\mathrm{BZ}$ associated with necrotrophs would be expected to be less effective under conditions of drought with resulting increased mortality. Vascular plugging and reduced hydraulic conductivity associated with vascular wilts would also be aggravated by drought. Although not specified as such in that framework [31•], tyloses and other plugging processes in response to vascular wilts are also part of the compartmentalization process.

Recent research by Park et al. [52•] and Park and Juzwik [53] on the apparent vascular wilt disease of hickory (Carya species) indicates a trade-off between compartmentalization and SW function. This form of hickory decline is associated 
with the canker fungus Ceratocystis smalleyi vectored by the hickory bark beetle (Scolytus quadrispinosis). In experimental trials with live trees, drill holes incubated with C. smalleyi produced larger columns of DW than water controls. Compartmentalization boundaries such as vascular plugs, lipid impregnation, tyloses, and occasional phenolic layers did occur with infection, but at a greater distance from the injection site. The columns of DW tended to coalesce causing a larger proportion of cross-sectional area of the stem to be reduced in hydraulic efficiency. Although fungus hyphae were clearly moving between cells and through cell lumens, the actual reduction in hydraulic flow was through shifts in tree metabolism that plugged the vasculature and resisted the spread of $C$. smalleyi. Those boundaries cut-off a volume of previously living SW from both the symplast and the apoplast. That represented a cost not only for the biosynthesis of stress metabolites, but also for hydraulic conductance and energy storage as well.

\section{Consequences of Interference with HW Formation}

For tree species that produce a characteristic colored HW such as oak, walnut, pine, red cedar, etc., the HW is especially valued for decay resistance as well as for the rich color. Heartwood formation is a vital process and requires living SW, dependent on orderly apoptosis [11]. Development of DW and HW kills living parenchyma and reduces SW crosssectional area and volume. In a static view of wood decay, these processes can be confused. This confusion is exacerbated by referring to DW as "false heartwood" when located in the same spatial position as SW or as "included sapwood" when located in the position of the HW core. The problem is that DW has neither the vital features of SW (water conduction, starch storage, living parenchyma, and dynamic response) nor the enhanced decay resistance of HW.

Shortle et al. [47] demonstrated this distinction in eastern red cedar (Juniperus virginiana L.). In eastern red cedar, the dark purplish decay resistant HW is especially valuable. In transverse section, light colored bands occurred occasionally within the HW core. Because of color and position, these bands (in transverse section) or columns (in 3 dimensions) within the HW were considered as "included sapwood" (Fig. 5). Recent research showed that the light-colored bands were DW that formed in the other band of SW. Because the DW was cut-off from the symplast and compartmentalization processes, that tissue did not mature into HW. As new rings of SW were formed to the outside of the DW, and that SW matured into $\mathrm{HW}$, the DW became progressively immersed in the stem cylinder [47]. These alternating bands of HW, DW, and voids produced by decay were described as "skeleton decay" in red cedar [54].

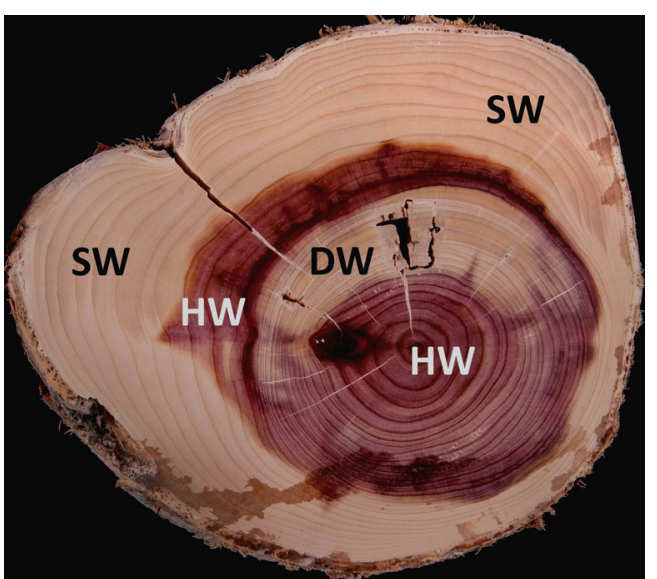

Fig. 5 Transverse section of Juniperus virginianum. The inner core of colored heartwood (HW) is interrupted by an arc of wound-initiated discolored wood (DW) which contains cubical cracking indicative of wood decay. Outside of the DW is an arc of HW and a continuous band of sapwood (SW). The check or crack at the 10 o'clock position is an artifact of drying

\section{Fire Injury}

For trees not killed outright, surface fire on the forest floor may kill all or some proportion of the VC along the circumference of the lower bole. The development of lengthy chronologies of forest fire incidence from the pattern of occurrence of fire scars in the tree-ring record testifies to the ability of individual trees to survive repeated wounding [55]. The initiation of cambial necrosis is an interaction of temperature and duration of exposure.

Following exposure to prescribed fire, injury, and associated defect including DW was effectively compartmentalized in butt logs of red oak [56]. Injury that occurred when the tree was of small diameter was effectively compartmentalized and had little effect on the value of sawn dimensional lumber as the DW and other wound-associated defects were sawn out and discarded during the milling process. In larger trees, defects from recent fire injury were similarly removed and discarded with the first slab on each face during milling. In merchantable logs that yielded sawn products with DW and associated defects, the loss in wood value was disproportionately greater than the loss of wood volume.

Resin ducts (RDs) in the phloem and in the axial and radial systems of wood are compartmentalization features of the Pineaceae that provide some degree of protection from the spread of insect pests and pathogens. Although varying somewhat in structure across species, RD in wood are formed schizogenously in both axial and radial orientations by separation of parenchyma cells early in the differentiation process. The duct is lined with an epithelium of parenchyma cells. RD formation may be constitutive (e.g., Pinus, Picea, Larix, and Pseudotsuga) or induced by wounding and are then referred to traumatic RD (e.g., Abies and Tsuga). The epithelial parenchyma 
form resin through shifts from primary metabolism to stress metabolism [25•].

RDs represent a structural cost in that RD does not contribute to hydraulic conductivity or mechanical stability [45]. RDs are also an ongoing metabolic cost for both the maintenance respiration of the epithelial parenchyma and the diversion of carbon to the biosynthesis of resin [25•]. Within the Pineaceae, there is an apparent range of allocation to constitutive and traumatic RD and resin production. Douglas-fir and western larch constitutively produce less resin than ponderosa pine, while producing greater numbers of axial traumatic $\mathrm{RD}$ [44]. Of the former two species, the larger traumatic RD of larch suggests a greater allocation of energy to defense after injury [45].

\section{Conclusion}

The recent review by Lachenbruch and McCulloh [5] emphasizes a hierarchical model for competitive fitness and continued plant viability in a changing environment. In that model, viability is determined by natural selection acting upon plant performance. Performance is built upon the interaction of hydraulic and mechanical properties with the environment. Those properties are determined by morphological traits. The physiological trade-offs in response to mechanical injury and infection represent a growth/defense trade-off that goes beyond biosynthetic costs to changes in allocation of tissue function. These shifts in function are affected by forest management practices and affect the economic value of wood products.

Acknowledgments I thank Kenneth R. Dudzik (Northern Research Station, US Forest Service, Durham, NH) for his expert photography and image processing.

\section{Compliance with Ethics Guidelines}

Conflict of Interest Dr. Smith has no conflicts of interests to declare.

Human and Animal Rights and Informed Consent This article contains no studies with human or animal subjects performed by the author.

\section{References}

Papers of particular interest, published recently, have been highlighted as:

- Of importance

•• Of major importance

1. Palacio S, Hoch G, Sala A, Körner C, Millard P. Does carbon storage limit tree growth? New Phytol. 2014;201:1096-100.
2. Stamp N. Out of the quagmire of plant defense hypotheses. Q Rev Biol. 2003;78:23-55.

3. Matyssek R, Koricheva J, Schnyder H, Ernst D, Munch JC, Oßwald $\mathrm{W}$, et al. The balance between resource sequestration and retention: a challenge in plant science. In: Matyssek R, Schnyder H, Ernst D, Munch JC, Oßwald W, Pretzsch H, editors. Growth and defence in plants. Berlin and Heidelberg: Springer; 2012. p. 3-24.

4. Herms DA, Mattson WJ. The dilemma of plants: to grow or defend. Q Rev Biol. 1992;67:283-35.

5. Lachenbruch B, McCulloh KA. Traits, properties, and performance: how woody plants combine hydraulic and mechanical functions in a cell, tissue, or whole plant. New Phytol. 2014; pp. 747764.

6. Weng J-K. The evolutionary paths towards complexity: a metabolic perspective. New Phytol. 2014;201:1141-9.

7. Weng J-K, Chapple C. The origin and evolution of lignin biosynthesis. New Phytol. 2010;187:273-85.

8. Martone PT, Estevez JM, Lu F, Ruel K, Denny MW, Somerville C, et al. Discovery of lignin in seaweed reveals convergent evolution of cell-wall architecture. Curr Biol. 2009;19:169-75.

9. Onofrejová L, Vašíčková J, Klejdus B, Stratil P, Mišurcová L, Kráčmar S, et al. Bioactive phenols in algae: the application of pressurized-liquid and solid-phase extraction techniques. J Pharmacol Biomed Anal. 2010;51:464-70.

10. Sørensen I, Pettlino FA, Bacic A, Ralph J, Lu F, O'Niell MA, et al. The charophycean green algae provide insights into the early origins of plant cell walls. Plant J. 2011;68:201-11.

11. Bollhöner B, Prestele J, Tuominem H. Xylem cell death: emerging understanding of regulation and function. J Exp Bot. 2012;63: 1081-94.

12. Fromm J. Xylem development in trees: from cambial divisions to mature wood cells. In: Fromm J, editor. Cellular Aspects of Wood Formation. Berlin and Heidelberg: Springer-Verlag; 2013. p. 3-39.

13. Spicer R, Groover A. Evolution of development of vascular cambia and secondary growth. New Phytol. 2010;186:577-92.

14. Groover A, Cronk Q. From Nehemiah Grew to genomics: the emerging field of evo-devo research for woody plants. Int J Plant Sci. 2013;174:959-63.

15. Spicer R. Symplasmic networks in secondary vascular tissues: Parenchyma distribution and activity supporting long-distance transport. J Exp Bot. 2014;65:1829-48.

16. Wiedenhoeft AC. Structure and function of wood-Chapter 3 of the Wood Handbook - Wood as an Engineering Material. Ross RR, editor. USDA For. Serv. Gen. Tech. Rep. FPL-GTR-190; 2010. p. $1-18$.

17. Conde E, Fang W, Hemming J, Willför S, Domínguez H, Parajó JC. Recovery of bioactive compounds from Pinus pinaster wood by consecutive extraction stages. Wood Sci Technol. 2014;48:311-23.

18. Kampe A, Magel E. New insights into heartwood and heartwood formation. In: Fromm J, editor. Cellular Aspects of Wood Formation. Berlin and Heidelberg: Springer-Verlag; 2013. p. 71-98.

19. Shigo AL, Hillis WE. Heartwood, discolored wood, and microorganisms in living trees. Ann Rev Phytopathol. 1973;11:197-222.

20. Cheynier V, Comte G, Davies KM, Lattanzio V, Martens S. Plant phenolics: recent advances on their biosynthesis, genetics, and ecophysiology. Plant Physiol Biochem. 2013;72:1-20.

21. Antilla A-K, Pirttilä AM, Häggman HM, Harju A, Venäläainen M, Haapala A, et al. Condensed conifer tannins as antifungal agents in liquid culture. Holzforschung. 2013;67:825-32.

22. Barbehenn RV, Constabel CP. Tannins in plant-herbivore interactions. Phytochemistry. 2011;72:1551-65.

23. Rodriques KCS, Lima JC, Fett-Neto AG. Oleoresins from pine: Production and industrial uses. In: Ramawat KG, Mérillon JM, editors. Natural Products. Springer-Verlag; 2013. p. 4037-4060. 
24. Tholl D. Terpene synthases and the regulation, diversity and biological roles of terpene metabolism. Curr Opin Plant Biol. 2006;9: 297-304.

25. Kolosova N, Bohlmann J. Conifer defense against insects and fungal pathogens. In: Matyssek R, Schnyder H, Ernst D, Munch JC, Oßwald W, Pretzsch H, editors. Growth and defence in plants. Berlin and Heidelberg: Springer; 2012. p. 85-109. This insightful chapter presents an integrated view of both constitutive and induced anatomical defenses for the broad range of fungi and insects that attack conifers.

26. Küster E. Pathological Plant Anatomy, Dorrance, F., Transl., G. Fischer, 1913.

27. Büsgen M, Münch E. The Structure and Life of Forest Trees, Thomson, T., Transl., Chapman \& Hall, 1929.

28. Hepting GH. Decay following fire in young Mississippi delta hardwoods. USDA Tech Bull no. 494, 1935, 32 pp

29. Shigo AL. Compartmentalization: a conceptual framework for understanding how trees grow and defend themselves. Ann Rev Phytopathol. 1984;22:189-214.

30. Byers BA, Ash SR, Chaney D, DeSoto L. First known fire scar on a fossil tree trunk provides evidence of late Triassic wildfire. Paleogeogr Paleoclim Paleoecol. 2014;411:180-7.

31. Oliva J, Stenlid J, Martinez-Vilalta J. The effect of fungal pathogens on the water and carbon economy of trees: implications for droughtinduced mortality. New Phytol. 2014;203:1028-35. This research review presents an innovative means to predict the effects of drought on disease severity and tree mortality through the trophic habit of pathogenic fungi.

32. Manion PD. Evolution of concepts in forest pathology. Phytopathological. 2003;93:1052-5.

33.• Shortle WC, Dudzik KR. Wood decay in living and dead trees: a pictorial overview. USDA For Serv Gen Tech Rep NRS-97, 2012. $26 \mathrm{pp}$. This well-illustrated treatment summarizes the compartmentalization process and builds upon the pioneering research in this strategy for tree survival.

34. Schwarze, F.W.M.R., Diagnosis and Prognosis of the Development of Wood Decay in Urban Trees, ENSPEC. 2008, 336 pp.

35. Deflorio G, Franz E, Beadle C, Mohammed C. Defence responses in plantation-grown Eucalyptus globulus and Eucalyptus nitens after artificial fungal inoculation. For Pathol. 2011;41:398-406.

36. Deflorio G, Franz E, Fink S, Schwarze FWMR. Host responses in the xylem of trees after inoculation with six wood-decay fungi differing in invasiveness. Botany. 2009;87:26-35.

37. Dujesiefken D, Liese W. The CODIT-Principle-New results about wound reactions of trees. Arborist News. 2011;20:28-30.

38. Vek V, Oven P, Humar M. Phenolic extractives of woundassociated wood of beech and their fungicidal effect. Int Biodeterior Biodegrad. 2013;77:91-7.

39. Oven P, Torelli N. Response of the cambial zone in conifers to wounding. Phyton. 1999;39:133-7.

40. Kiser J. Histochemical and geometric alterations of sapwood in coastal Douglas-fir following mechanical damage during commercial thinning. Silvae Fenn. 2011;45:729-41.
41. Nagy NE, Ballance S, Kvaalen H, Fossdal CG, Solheim H, Hietala AM. Xylem defense wood of Norway spruce compromised by the pathogenic white-rot fungus Heterobasidion parviporum shows a prolonged period of selective decay. Planta. 2012;236:1125-33.

42. Shortle WC, Smith KT, Dudzik KR. Tree survival 15 years after the ice storm of January 1998. USDA For Serv Res Pap NRS-25, 2014, $4 \mathrm{pp}$.

43. Fink S. Pathological and regenerative plant anatomy. Gebruder Borntraeger. 1999, $1095 \mathrm{p}$.

44. Arbellay E, Stoffel M, Sutherland EK, Smith KT, Falk DA. Changes in tracheid and ray traits in fire scars of North American conifers and their ecophysiological implications. Ann Bot. 2014;114:223-32.

45. Arbellay E, Stoffel M, Sutherland EK, Smith KT, Falk DA. Resin duct size and density as ecophysiological traits in fire scars of Pseudotsuga menziesii and Larix occidentalis. Ann Bot. 2014;114:973-80

46. Parfitt D, Hunt J, Dockrell D, Rogers HJ, Boddy L. Do all trees carry the seeds of their own destruction? PCR reveals numerous wood decay fungi latently present in sapwood of a wide range of angiosperm trees. Fungal Ecol. 2010;3:338-46.

47. Shortle WC, Dudzik KR, Smith KT. Development of wood decay in wound-initiated discolored wood of eastern red cedar. Hozforschung. 2010;64:529-36.

48. Havreljuk F, Achim A, Pothier D. Regional variation in the proportion of red heartwood in sugar maple and yellow birch. Can J For Res. 2013;43:278-87.

49. Johansson T, Hjelm B. Frequency of false heartwood of stems of poplar growing on farmland in Sweden. Forests. 2013;4:28-42.

50. Yanai RD, Germain RH, Anderson NM, Coates TA, Mishler AK. Heart size of sugar maple sawlogs across six northern states. J For. 2009;107:95-100.

51. Baral SK, Schneider R, Pothier D, Berninger F. Predicting sugar maple (Acer saccharum) discoloured wood characteristics. Can J For Res. 2013;43:649-57.

52. Park J-H, Juzwik J, Cavender-Bares J. Multiple Ceratocystis smalleyi infections associated with reduced stem water transport in bitternut hickory. Phytopathology. 2013;103:565-74. This research paper presents a precise histological view of the pathology caused by a canker fungus that also causes a vascular wilt. Although this disease is not widely known now, it is likely to be regarded as a significant factor in hickory mortality in the future.

53. Park J-H, Juzwik J. Ceratocystis smalleyi colonization of bitternut hickory and host responses in the xylem. For Pathol. 2014;44:28292.

54. Smith KT, Glaeser JA. Skeleton decay in eastern red cedar. Arborist News. 2013;22:32-4.

55. Margolis EQ, Swetnam TW. Historical fire-climate relationships of upper elevation fire regimes in the south-western United States. Int J Wildl Fire. 2013;22:588-98.

56. Marschall JM, Guyette RP, Stambaugh MC, Stevenson AP. Fire damage effects on red oak timber product value. For Ecol Manage. 2014;320:182-9. 